\title{
国art Eecono.
}

\section{REVIEWS.}

Seventeenth Annual Report of the General Board of Commissioners in Lunacy for Scotland. Edinburgh: 1875.

THis is as usual a very elaborate report, and contains a great deal of information which one working at the statistics of lunacy would like to have; but, in common with most documents printed at the public expense, it might be improved by condensation. Many of the statistical tables are well framed and useful, but nobody would complain if others of them were left out.

The total number of lunatics known to the Board of Lunacy is 8069 , of whom 6563 are supported from parochial rates. The number of the unreported insane is estimated at 2000, of whom the larger proportion belong to a class little removed from pauperism. The gradual passing of this class into asylums is probably one great cause of the apparent increase of insanity.

One noticeable change in the treatment of insanity is the abolition of airing courts. This measure was first used by Dr Sibbald at the Argyll and Bute Asylum, who, finding his patients could get on well enough without an airing court, never built one; and when he became a deputy-commissioner, he no doubt induced his colleagues to assist in gaining farther trials for the experiment. Airing courts have since been given up in the Inverness, Perth, Fife, and Haddington Asylums, and we understand the superintendents look favourably upon the new system. Generally, the advocates of a change overstate the advantages to be derived from adopting it. We have a strong feeling that airing courts cannot be dispensed with in large asylums situated in populous districts. It might happen too, that while some patients would prefer being walked about guarded and watched by a sufficient number of keepers, this would be irksome and exasperating to others; and that some who might be allowed to go into the airing court would, if taken about the grounds, be so noisy and troublesome, or so determined in their attempts to escape, that they would soon be left under lock and key, and get no open-air exercise whatever. The experiment has only been tried in asylums situated in the country. It would perhaps be well to wait a few years longer before claiming it as finally successful.

The feature which excites interest in the Scottish Lunacy Reports is the system of boarding out insane patients in private houses. This is done principally in poor and remote places, such as the Highlands and islands; for, where the people are well-to-do, 
they will not take such inmates at low rates. These pauper lunatics are visited once a year. This appears a very small amount of inspection, but it is likely enough that those who take in the boarders would throw up the business if they were exposed to much additional surveillance.

Great credit is due to the superintendents of asylums, who generally select the patients thought fit to be boarded out. It ought to be carefully borne in mind that it is the district and pauper asylums which take in the worst and most dangerous cases-those of acute mania, general paralysis, or determined suicidal insanity-which try so heavily the skill, patience, and attention of the doctor of the asylum, and add so largely to the bill of mortality and record of accidents. The cases in the lunatic wards of poorhouses are easier managed and less likely to sink under the attacks of disease; and those in private dwellings, being the most harmless, not subject to dangerous diseases, and being returned to the asylums when they become unmanageable, or are visited by dangerous diseases, the argument in favour of the system of boarding out pauper lunatics, from their death rate being lower than that of patients in public asylums or in the lunatic wards of poorhouses, seems to us of no value. The mortality of these boarders is given at 5.8 per cent.; in public asylums it is 8.8 per cent. for the males and 8 for the females. In the lunatic wards of poorhouses it is 8.1 for the males, and 7.4 for the females. We think that the Deputy-Commissioners would make their case look better if they showed less anxiety to plead it. They admit that there are evils connected with the boarding-out system, and we do not think these evils so great that they could not afford to state them in set terms.

Dr Sibbald has an interesting paper on the Distribution of Lunacy in Rural and Urian Districts. He thinks that insanity is more common in towns than in country districts, and that this greater frequency occurs in connexion with physical degeneracy of race and excessive mortality.

The Commissioners consider that the grant from Government for pauper lunatics, to diminish the local rates, is not a wise measure, and point out in forcible terms the evil consequences that may be expected to flow from it.

After enumerating the accidents reported to them as occurring in asylums, they observe- " Possibly, the number of accidents among the insane, instead of being diminished, may be increased by congregating them in asylums, a system which is not natural, and which is chiefly recommended by convenience and economy." We do not know what the natural system of disposing of the insane may be, but we are sure that at present asylums are the best system that is practicable. No management will ever be so perfect as to save those surrounded by violent maniacs from occasional injury, or prevent determined suicides from now and then succeeding in hurting or destroying themselves; but we believe

vOL. XXI. - NO. XI. 
that, in the main, the asylums of Scotland, both public and private, are ably managed by hardworking and skilful superintendents, well trained in their profession. It is to the incessant application of their knowledge and judgment that the insane are so well cared for, not by the application of fixed rules. Every one is ready to admit, in theory at least, that when an undertaking is going on well, and is in good hands, liberty ought to be carefully respected. Freedom of treatment is a prime consideration, if a thing is to be done well, and we believe that a superintendent has many means of arriving at a just conclusion, on which an inspector in his hurried visit could neither take up nor be taught. It seems to us, therefore, that the Commissioners should not forget general success in their scrutiny of minute details.

The Superannuation of Officers in British Hospitals for the Insane: Its Principle, Policy, and Practice. By W. Lauder Lindsay, M.D., F.R.S.E. London: 1875.

THose who are connected with lunatic asylums have much reason to thank Dr Lindsay for the great amount of information he has collected about the salaries and allowances of officials. It is often a subject of some difficulty what wages should be offered for any particular duty, and Dr Lindsay's extensive tables, which he has collected with so much trouble, will often be of great assistance to the superintendents of asylums. Dr Lindsay advocates the granting of liberal retiring allowances to all the officials, high and low, as a means of attracting and keeping good servants. Dr Lindsay has been always distinguished for the disinterestedness of his character, and the courage and independence with which he has upheld the dignity of his profession. He gives a true and striking sketch of the difficulties, trials, and worries, which surround the medical superintendent of an asylum.

Extrauterine Pregnancy: its Causes, Species, Pathological Anatomy, Clinical History, Diagnosis, Prognosis, and Treatment. By JoHn S. Parry, M.D., etc., etc. London: Lewis : 1876.

Since the Edinburgh memoir of Dr Campbell, published in 1840, there has appeared no such comprehensive and valuable work on this subject as that to which we now call attention by Dr Parry of Philadelphia.

Since Campbell's time, our knowledge has greatly increased over the whole field, and almost all the novelty has been faithfully swept 